\title{
Regional frequency analysis for mapping drought events in
} north-central Chile

by

4 J. H. Núñez ${ }^{1}$, K. Verbist $^{2}$, J. R. Wallis ${ }^{3}$, M.G. Schaefer $^{4}$, L. Morales ${ }^{5}$ and W.M. Cornelis $^{2}$

51 Water Center for Arid and Semi-Arid Zones of Latin America and the Caribbean,

6 Benavente 980, La Serena, Chile, jnunez@ cazalac.org. Correspondence author.

72 Department of Soil Management, Ghent University, Coupure links 653, 9000 Ghent,

8 Belgium, Koen.Verbist@UGent.be, Wim.Cornelis@UGent.be

93 Yale University, New Haven, CT, USA, ludlowvt@gmail.com

104 MGS Engineering Consultants, Olympia, WA, USA, mgschaefer@mgsengr.com

115 Agriculture Sciences Faculty, University of Chile, Av. Santa Rosa, 11315, Santiago,

12 Chile, 1morales@ renare.uchile.cl

13

14 Correspondence to:

15 Jorge H. Nuñez

16 e-mail: jnunez@ cazalac.org

17 Phone: 56-51-334812

18 Fax: 56-51-204492

\section{Abstract}

21 Droughts are among the most important natural disasters, particularly in the arid and

22 semiarid regions of the world. Proper management of droughts requires knowledge of the

23 expected frequency of specific low magnitude precipitation totals for a variety of durations.

24 Probabilistic approaches have often been used to estimate the average recurrence period of

25 a given drought event. However, probabilistic model fitting by conventional methods, such

26 as product moment or maximum likelihood in areas with low availability of long records 
27 often produces highly unreliable estimates. Recognizing the need for adequate estimates of 28 return periods of severe droughts in the arid and semiarid region of Chile, a regional 29 frequency analysis method based on L-moments (RFA-LM) was used for estimating and 30 mapping drought frequency. Some adaptations to the existing procedures for forming 31 homogeneous regions were found necessary. In addition, a new 3-parameter distribution, 32 the Gaucho, which is a special case of the 4-parameter Kappa distribution, was introduced, 33 and the analysis procedure was improved by the developments of two new software tools 34 named L-RAP, to perform the RFA-LM analysis, and L-MAP, to map the resulting drought 35 maps. Eight homogeneous sub-regions were delineated using the Gaucho distribution and 36 used to construct return period maps for drought events with $80 \%$ and $40 \%$ precipitation of 37 the normal. The study confirms the importance of a sub-regional homogeneity test, and the 38 usefulness of the Gaucho distribution. The RFA-LM showed that droughts with a $40 \%$ 39 precipitation of the normal have return periods that range from four years at the northern 40 arid boundary of the study area to 22 years at the southern sub-humid boundary. The results 41 demonstrate the need for different thresholds for declaring a drought than those currently in use for drought characterization in north-central Chile.

44 Keywords: L-moments; drought frequency; semiarid; precipitation; regional frequency 45 analysis; Chile

\section{1. Introduction}

48 Meteorological droughts, the result of a precipitation deficit with respect to what is 49 considered "normal" (Seth, 2003; Wilhite and Buchanan-Smith, 2005) are natural disasters 50 which historically have affected large populations (and make up to 35\% of those affected 51 by natural disasters), often resulting in significant fatalities (50\% of the mortality due to natural disasters), whereas $7 \%$ of world economic losses have been attributed to their

53 occurrence (Below et al., 2007). These economic losses are likely to be higher because it is 54 assumed that the indirect impacts are generally much more complex to evaluate than the direct consequences (Ponvert-Delisle et al., 2007). 
56 Droughts can be characterized by their frequency, intensity and duration (Wilhite and 57 Buchanan-Smith, 2005), as well as by the vulnerability of communities to drought impacts 58 (Luers et al., 2003; Luers, 2005). Droughts can also be defined in agricultural terms based 59 on a deficit in plant-available water, and in hydrological terms based on a deficit in 60 streamflow. Drought frequency, both meteorological and hydrological, has been analyzed 61 using a variety of probabilistic models, all of which allow probabilistic information present 62 in the sample to be summarized (Chow et al., 1994; Demuth and Külls, 1997; Fernández 63 and Vergara, 1998; Hisdal and Tallaksen, 2003; Loukas and Vasiliades, 2004; Serinaldi et 64 al., 2009; Türk and Tatl, 2009). From the different probability approaches commonly used 65 in hydrologic frequency assessment, the Index Flood Regional Frequency Analysis based 66 on an L-moments procedure (RFA-LM), appears to provide the most robust estimates of 67 meteorological drought frequencies (Hosking et al., 1985a). The advantages of regional 68 frequency analysis, as well as L-moments have been recognized by several authors 69 (Ciumara, 2007; Delicado and Goria, 2007; Hosking and Wallis, 1997; Kysely et al., 2010; 70 Liou et al., 2008; Loucks and Van Beek, 2005; Mishra et al., 2007; Norbiato et al., 2007;

71 Sankarasubramanian and Srinivasan, 1999; Stedinger et al., 1993).

72 In recent years, the RFA-LM methodology has been applied in preparing the U.S. Drought 73 Atlas (Werick, 1995), meteorological drought analysis in northwestern Mexico (Hallack74 Alegria and Watkins, 2007) and Turkey (Yurekli and Anli, 2008), hydrological drought 75 analysis in southern Germany (Demuth and Kulls, 1997) and New Zealand (Pearson, 1995), 76 and compared with other regionalization alternatives in European drought studies 77 (Tallaksen and Hisdal, 1997; Tallaksen and Hisdal, 1999).

78 However, little work has been done on the application of RFA-LM for regional drought 79 probability studies for arid and semiarid areas. These areas are the most vulnerable to 80 drought because of the naturally limited precipitation supply. This is further exacerbated by 81 their extreme spatial and temporal variability of precipitation (Kalma and Franks, 2003). 82 Modarres (2009), for example, applied RFA-LM in the study of dry spells in the semiarid 83 region of Iran. However, the author used at-site statistics in cluster and principal 84 components analysis to check the presence of smaller homogeneous regions inside a 85 previously well defined homogeneous region. This approach is inconsistent with the basic 86 assumption of the index flood procedure where all sites within a homogeneous region have 
87 identical probability distribution (Reed et al., 1999; Stedinger et al., 1993) and the fact that

88 at-sites statistics are not recommended to be used in homogeneous regions formation

89 (Hosking and Wallis, 1997).

90 In another study, Vicente-Serrano (2006) applied RFA-LM to determine the best-fit

91 distribution in the calculation of the Standardized Precipitation Index (SPI) for different

92 time scales in the Iberian Peninsula. However, the author did not include confirmation of

93 regional homogeneity in his analysis. He also based the choice of the best-fit distribution

94 solely on the appearance of the L-moment ratio diagram. Hosking and Wallis (1997) and

95 Peel et al. (2001) consider this approach insufficient for a proper choice of the best-fit

96 distribution.

98 In the RFA-LM application to drought and other hydrological events, various criteria have 99 been used to help form homogeneous regions. Some authors have included the use of 100 cluster analysis (Burn and Goel, 2000), the region of influence (Gaál et al., 2007; Gaál and 101 Kyselý, 2009), fuzzy logic (Chavochi and Soleiman, 2009), self-organizing maps (Lin and 102 Chen, 2006) and the seasonality index (Kohnová et al., 2009) amongst the various schemes 103 described by other authors (Burn and Goel, 2000; Reed et al., 1999). However, most of 104 these methods are based on multivariate procedures, like cluster analysis, which do not 105 reveal the physical reasons why these regions should be considered homogeneous (Clarke, 106 2010).

107 Although the RFA-LM methodology allows the incorporation of new general and flexible 108 distribution models, homogeneity issues have not been previously explored in 109 meteorological drought probability analysis of arid and semiarid regions.

110 Similarly, few studies have spatially mapped drought quantiles or return periods derived 111 from the application of RFA-LM. Spatial mapping of drought characteristics using 112 Geographic Information Systems (GIS) in combination with RFA-LM can be a powerful 113 tool for drought risk management programs. Some studies have considered this aspect in 114 the analysis of hydrological events, such as mapping the expected maximum short period 115 rainfall for a given frequency in the U.S. (Schaefer et al., 2008; Wallis et al., 2007) and 116 the mapping of the return period of dry spells in northeast Spain (Lana et al., 2008). 
117 In this context, this paper proposes some modifications to the application of RFA-LM in

118 the evaluation and mapping of meteorological drought frequency in north-central Chile.

119 The robustness of extreme droughts estimation becomes critical in arid and semiarid

120 regions, where the only available data source are short monthly precipitation records

121 provided by a regionally scattered meteorological stations network. This study proposes a

122 simplified procedure for homogeneous region formation, the adaptation of a specific case

123 of the 4-parameter Kappa distribution, i.e. the 3-parameter Gaucho distribution, to obtain a

124 best-fit regional probability distribution for drylands and tools to produce meteorological

125 drought return period maps.

\section{2. Methodology}

\section{2.1. Characteristics of the study area}

129 2.1.1. Geographic characteristics

130 The study area is located in north-central Chile (Fig.1) and covers an area of 88,766 $\mathrm{km}^{2}$.

131 According to di Castri and Hajeck (1976) and Verbist et al. (2006), this area includes the arid

132 regions at its northern boundary, with 9-10 dry months per year, and the semi-arid to sub

133 humid regions on the southern boundary, with 5-6 dry months per year. Geographically, the

134 region is located between latitudes $29^{\circ} 01^{\prime}$ and $34^{\circ} 54^{\prime}$ South and between longitudes $69^{\circ} 50^{\prime}$

135 and $72^{\circ} 04^{\prime}$ West. Elevation ranges from sea level to $6206 \mathrm{~m}$ at the highest part of the Andes.

\section{2.1.2. Mean Annual Precipitation}

138 Mean annual precipitation (MAP) (Fig.1) shows both a North-South and an East-West 139 gradient, with a minimum of $50.6 \mathrm{~mm}$ in the far North and a maximum of $1055.6 \mathrm{~mm}$ at the 140 southern edge of the study area. The extra-tropical frontal disturbances associated with the 141 winter rains and the windward orographic rainfall formation due to the Andes explain the 142 increase in the MAP from north to south and from the sea to the Andes (Rutllant, 2004). 143 This spatial pattern and temporal dynamics are linked with the general circulation of the 144 atmosphere in this area, and may be adversely affected by conditions of negative anomaly 145 in sea surface temperatures associated with La Niña-ENSO phenomenon events, causing 
146 reductions of more than $60 \%$ of annual precipitation (Escobar and Aceituno, 1998;

147 Quintana, 2000; Rutllant, 2004; Squeo et al., 2006; Verbist et al., 2010).

\subsubsection{Data sources}

150 For this study, 54 stations with daily precipitation records and 126 stations with monthly

151 precipitation records were available. This provided a total of 180 meteorological stations

152 distributed throughout the study area, with data provided by the Water General Directorate

153 (DGA) and the Meteorological Directorate of Chile (DMC).

154 Precipitation records at daily stations were aggregated to produce monthly values, but only 155 for months where there were complete daily records. If daily data were missing from a 156 month, that month was not included in the analysis. The 180 stations had an average record 157 length of 28.1 years, with a minimum of two years and a maximum of 75 years. $50 \%$ of the 158 stations had 25 or fewer years-of-record.

159 In order to establish the final database for the RFA-LM procedure, we selected those

160 stations that had a minimum record length of 15 years. This criterion was obtained using 161 record curves, similar to those used by Bonnin et al. (2006). Selecting an appropriate 162 minimum record length is important as it influences the number of stations for analysis as 163 well as the total years of record, both affecting the reliability of the quantile estimates 164 (Hosking and Wallis, 1997; Mishra et al., 2007). On this basis, 172 stations were selected 165 for analysis.

167 2.2. Adapted RFA-LM procedure

168 The RFA-LM procedure used in this study was based on the methods proposed by Hosking 169 and Wallis (1997) and the idea that the L-moments ratios L-Cv and L-skewness, defined as 170 L-coefficient of variation and L-coefficient of skewness, respectively, are mapable 171 quantities in their own right (Wallis et al., 2007). The five steps in the analysis procedure 172 were:

173 1. data assembly, data screening and quality checking,

1742 . identification of homogeneous regions, 
3. selection of the regional frequency distribution,

176 4. estimation of distribution parameters and the quantile function, and

177 5. spatial mapping of L-moment and drought characteristics.

178 These five steps are presented below.

\subsubsection{Stage 1: Data screening and quality checking}

181 Considerable efforts were made in the screening and quality checking of precipitation data, 182 which aimed at eliminating false values associated with a wide variety of data 183 measurement, recording and transcription errors. Special emphasis was given to the 184 confirmation of the basic assumptions of homogeneity, using double mass curve analysis 185 (WMO, 1994); stationarity, using linear regression analysis; and autocorrelation, using the 186 Lag-1 test for serial independence (Wallis et al., 2007).

187 As a quality control tool, the discordancy measure (Di) from Hosking and Wallis (1997)

188 was used to identify those stations for which sample L-moments were significantly 189 different from the observed pattern of the other sites within the region.

191 2.2.2. Stage 2: Formation and acceptance of homogeneous sub-regions

192 2.2.2.1. Formation of candidate homogeneous sub-regions

193 A homogeneous sub-region is herein defined as a group of sites (stations) whose data, after 194 rescaling by the at-site mean, can be described by a common probability distribution 195 (Hosking and Wallis, 1997; Stedinger et al., 1993; Brath et al., 2001). This is often termed as 196 the Index Flood (Stedinger et al., 1993) approach to regional frequency analysis. In addition, 197 the site data must satisfy the homogeneity criterion $\mathrm{H} 1$ originally defined by Hosking and 198 Wallis (1997).

199 A heterogeneous super-region is herein defined as a geographic area composed of 200 homogeneous sub-regions whose data can be described by the same probability 201 distribution. Depending on the complexity of the phenomenon being analyzed, the study 202 area may be comprised of one or more heterogeneous super-regions. 
203 In this paper we propose using a seasonality index and the magnitude of MAP as criteria for

204 forming homogeneous sub-regions. A similar approach was suggested by Kohnová et al.

205 (2009), but using measures of seasonality in regional stream flow frequency analysis.

206 The procedure we used was thus as follows:

207 a) For each station, a Seasonality Index (SI), the Julian Mean Day (JMD) and MAP 208 were calculated. The SI and JMD calculations are described by Dingman (2001) and 209 Schaefer et al. (2008) and are based on circular statistics which yield the average day 210 of occurrence, analogous to the arithmetic mean for dates, and SI, similar to a 211 standardized measure of variation. The SI takes values between 0 and 1 . Values near 0 212 indicate a wide variation in the time-of-year of occurrence, while values close to 1 213 indicate small variation in the time-of-year of occurrence and therefore a high seasonal 214 concentration of data (Schaefer et al., 2008).

215 b) Based on SI values and their corresponding precipitation histograms for a large set of 216 precipitation stations, a criterion for pooling stations into homogeneous sub-regions was 217 defined: Group 1, stations with SI from 0 to 0.2; Group 2, with SI between 0.2 and 0.6; 218 and Group 3 with SI greater than 0.6. This grouping ensures that stations that have 219 different rainfall forming processes are separated, since no distribution can fit to station 220 data belonging to two or more of these different groups simultaneously.

221 c) In the event that stations are all within the same SI range, they can be further 222 partitioned according to their JMD values. This is appropriate because there may be 223 stations with similar SI values but whose rainfall concentration occurs at different times 224 of the year (areas with rainfall concentrated in summer and others with rainfall 225 concentrated in winter which can have different moisture sources, storm intensities and 226 durations).

227 d) Finally, stations with similar SI and JMD values can be further partitioned into 228 candidate homogeneous sub-regions according to the magnitude of MAP. This 229 approach is based on the finding that the shape of the regional probability distribution is 230 often related to the magnitude of MAP. Specifically, it is expected that data from semi231 arid regions show greater variability, higher skewness and different probability 232 distribution shapes than data from more humid regions, as has been indicated by several 
authors (Eriyagama et al., 2009; Fuentes et al., 1988; Gastó, 1966; Kalma and Franks, 2003; Le Houérou, 1988; Schaefer et al., 2008). To accommodate this behavior, stations were ordered from lowest to highest magnitude of MAP and grouped to form a suitable number of sub-regions with similar sample size.

e) Homogeneous sub-regions need not be geographically continuous (Hosking and

\subsubsection{Acceptance of candidate homogenous sub-regions}

242 The homogeneity of each sub-region was confirmed using the H1 heterogeneity measure of 243 Hosking and Wallis (1997). The H2 heterogeneity measure was not used because it has 244 proven to lack statistical power (Viglione et al., 2007).

245 A sub-region was accepted as homogeneous where $\mathrm{H} 1<2$, possibly heterogeneous with $2462<\mathrm{H} 1<3$ and as a heterogeneous, if $\mathrm{H} 1>3$. The selection of these thresholds was based on 247 recommendations from Wallis et al. (2007) which account for site-to-site variability 248 resulting from data measurement and recording errors in addition to statistical variability.

\subsubsection{Stage 3: Selection of regional probability distribution}

251 The selection of the best-fit regional probability distribution function was based on 252 screening L-moment ratio diagrams. The final decision was based on the $Z^{\mid \text {DIST| }}$ goodness253 of-fit test described by Hosking and Wallis (1997) as applied to all of the homogeneous 254 sub-regions within a heterogeneous super-region.

255 The distributions that were examined included the Generalized Pareto, Generalized 256 Extreme Value, Generalized Normal, Pearson Type III, Generalized Logistic, and the 4257 parameter Kappa distribution (4-p-Kappa) as well as the 3-parameter Gaucho distribution 258 described in detail below. The application of L-moments to estimate the parameters of these 259 and other distributions has been described by several authors (Abdul-Moniem and Selim, 260 2009; Delicado and Goria, 2007; Kundu, 2001; Hosking and Wallis, 1997; Shawky and 261 Abu-Zinadah, 2009). 
262 In this study, we also proposed a new distribution based on a modification to the 4-p-Kappa 263 distribution described by Hosking (1994), in which the second shape parameter, $h$, was set

264 to a value of 0.50 . This special case of the 4-p-Kappa distribution is called the "Gaucho 265 distribution", whose inverse function is as follows:

$$
q(F)=\xi+\frac{\alpha}{\kappa}\left\{1-\left(\frac{1-F^{0.50}}{0.50}\right)^{\kappa}\right\}
$$

269 where $q(F)$ is the Gaucho quantile function, $F$ is the non-exceedance probability for the 270 desired quantile, $\xi$ and $\alpha$ are the location and scale parameters, $\kappa$ is the first shape 271 parameter, and the second shape parameter $h$ for the 4-p-Kappa distribution is set to a value 272 of 0.50 .

273 Thus, the Gaucho distribution constitutes a three-parameter distribution which can be 274 represented in an L-moments ratio diagram as bisecting the space between the Generalized 275 Pareto and Generalized Extreme Value distributions.

276 Although several probability distributions might be statistically acceptable for each 277 homogeneous sub-region based on the $\mathrm{Z}^{|\mathrm{DIST}|}$ goodness-of-fit measure, the adopted regional 278 probability distribution was selected as the distribution most frequently accepted by the 279 collection of homogeneous sub-regions within the heterogeneous super-region.

\subsubsection{Stage 4: Estimation of distribution parameters and quantiles}

282 After the regional probability distribution was selected, the distribution parameters for each 283 homogeneous sub-region were determined by the method of L-moments as described by 284 Hosking and Wallis (1997). The inverse function could then be expressed in dimensionless 285 form (Eq. 2), which is termed a regional growth curve (Hosking and Wallis, 1997; 286 Stedinger et al., 1993): 
289 where $\hat{Q}_{i}(F)$ is the quantile function for station $i, \hat{\mu}_{i}$ is the at-site mean for station $i, \hat{q}(F)$ is 290 the regional growth curve.

292 Site-specific quantile estimates for annual precipitation were obtained by multiplying the 293 regional growth curve by the at-site value of mean annual precipitation (MAP). For the case 294 of sites with station data, the MAP value obtained from the station data was used to scale 295 the regional growth curve. For ungauged sites, the at-site MAP value was estimated using a 296 topoclimatics interpolation method as described by Morales et al. (2006).

\subsubsection{Stage 5: Mapping}

299 Spatial mapping of various proportions of annual precipitation is helpful in depicting the 300 frequency of precipitation deficits throughout the study area. Color-shaded maps were 301 generated depicting the return periods for values of $80 \%$ and $60 \%$ of mean annual 302 precipitation (20\% and $40 \%$ precipitation deficits). This is consistent with the concept of 303 defining drought thresholds as some percentage of the most recent 30-year climatic normal 304 for mean annual precipitation (Quiring, 2009a).

305 To construct the maps, we first developed relationships between L-moment ratios and MAP 306 for the homogeneous sub-regions. This is an approach used in several studies that have 307 shown that MAP is often a good explanatory variable for describing the spatial variability 308 of the L-moment ratios (Baldassarre et al., 2006; Schaefer et al., 2008; Wallis et al., 2007).

309 The procedures for spatial mapping of quantile estimates and return periods using 310 relationships between L-moment ratios and MAP are described in Wallis et al. (2007).

311 These spatial mapping procedures consisted of:

312 a) Determining predictive relationships between sub-regional values of $\mathrm{L}-\mathrm{Cv}$ and 313 MAP, and L-skewness and MAP such as described by Eq. 3. We also created two 314 additional "extreme sub-regions" to facilitate predictions and mapping near the extreme 315 ends of the available data. These "extreme sub-regions" were obtained by combining 316 the eight stations with least MAP, and the eight stations with the highest MAP to form 
two additional sub-regions. Regional values of the L-moment ratios were computed for

318 these two sub-regions as described previously. The function selected for describing the relationship between L-moment ratios and MAP was as follows :

$$
\mathrm{L}-\text { Moment } \text { ratio }=\alpha e^{-\beta(M A P)}+\delta
$$

where $\alpha, \beta$ and $\delta$ are fitting parameters. Their values were determined by least-squares optimization using Excel's Solver tool. As a measure of goodness-of-fit, the RMSE and Standardised RMSE (RMSE $)$ were used (Schaefer et al., 2008).

b) A raster grid map of MAP for the study area was constructed by multiple regression analysis using a topoclimatics information procedure as described by Morales et al. (2006).

334

c) From the gridded map of mean annual precipitation, and using the prediction function (Eq. 3), L-Cv and L-skewness values were generated for each cell of the raster map of MAP.

d) Maps of drought return periods were generated by first solving for the distribution parameters for each grid-cell based on grid-cell values of L-Cv and L-skewness, and then solving for the non-exceedance probability $(F)$ using the cumulative distribution function for the selected regional probability distribution.

341 a) It has a friendly graphical user interface, which facilitates use by analysts not familiar 342 with the use of FORTRAN or other routines.

343 b) L-RAP proceeds step-by-step through each of the stages associated with RFA-LM. 344 This begins with an EXCEL template for data import, data quality control, checking of 
the assumptions of stationarity and independence, computation of the SI, JMD, Di and heterogeneity indices, computation of goodness-of-fit measures for selection of the regional probability distribution, computation of distribution parameters and quantiles.

For the preparation of the return period maps, we developed a software tool called L-MAP

354 (Verbist, 2010). It is based on the L-RAP algorithms, and it can import an IDRISI binary 355 type format base map and use it for spatial mapping of L-moment ratios, return periods and 356 precipitation quantiles.

\section{Results}

\subsection{Stage 1: Data screening, preparation and assumptions checking}

361 stations have an average record length of 29.2 years and totaled 5015 station-years of 362 record. This dataset yielded an average MAP of $359.4 \mathrm{~mm}$, with a minimum of $50.6 \mathrm{~mm}$ 363 and a maximum of $1055.6 \mathrm{~mm}$. Tests for stationarity and serial independence were 364 conducted on the collection of 172 stations, and showed that most stations (94\%) passed the 365 test for stationarity and serial independence (99\%). As such, the time-series of annual 366 precipitation data were deemed to be stationary and serial independent.

\subsection{Stage 2: Formation and acceptance of homogeneous sub-regions}

\subsubsection{Analysis of seasonality and MAP for forming homogeneous sub-regions}

371172 stations. Frequency histograms of SI and JMD as well as scatterplots and linear 372 regression analysis between these variables and MAP are shown in Fig. 2. The purpose of 
373 this analysis was to detect any changes in SI and JMD along a precipitation gradient which 374 increases from the driest (in the North) to the wettest portions of the study area in the 375 South. The SI showed an average of 0.87 , with a minimum of 0.72 and a maximum of

376 0.94. This implies a high concentration of rainfall in a few months. In fact, Aceituno (1992) 377 showed that in Chile, between latitudes $30^{\circ}$ and $35^{\circ} \mathrm{S}$, rainfall occurs mainly in the winter 378 months of June to August.

379 Huanta, Ramadilla, San Gabriel and Farellones Ski stations exhibit the four lowest SI 380 values. These four stations are located in mid-mountain areas of the Andes. It is possible 381 that these stations receive summer rainfall of convective origin, affecting their seasonality, 382 although Garreaud and Rutllant (1997) indicated that summer rainfall does not represent 383 more than $5 \%$ of the annual precipitation total.

384 The JMD showed an average of day 180 with a minimum and a maximum of day 157 and 385 day 191 respectively, and a small coefficient of variation of $2.6 \%$. That is, the rainy season 386 in Chile is concentrated around the $30^{\text {th }}$ of June (day 180). The lower values of JMD of two 387 stations, one of which is also the Ramadilla station, could suggest different behavior in 388 their seasonality of precipitation or problems with data quality. The discordancy measure 389 Di will be used in a later step to assist in determining if these two stations should be 390 included or excluded from the analysis of the study area.

391 Verbist et al. (2006) have shown that the number of months with precipitation increases 392 from north-to-south in the study area as does the precipitation amount in the wettest month. 393 However, Figs. 2b and 2d show that the SI and JMD do not vary with mean annual 394 precipitation from north-to-south across the study area. This finding is consistent with the 395 effect of the atmospheric general circulation in Chile where rainfall is concentrated in the 396 winter season and interannual variability is exclusively associated to a gradient of annual 397 precipitation, mainly in the north-south direction (Fuentes et al., 1988). Thus, the entire 398 study area can be considered to have the same seasonality of precipitation.

399 These findings indicate that the study area is comprised of one heterogeneous super-region 400 containing several homogeneous sub-regions. The homogeneous sub-regions were formed 401 based on grouping of stations within a similar range of MAP. 


\subsubsection{Choice of the number of homogeneous sub-regions}

404 The determination of the number of candidate sub-regions was based on finding a balance 405 between providing a sufficient number of sub-regions to develop a reliable predictor 406 equation for L-Cv and L-Skewness relationships for spatial mapping (Eq. 3), and having 407 sufficient stations within a sub-region to reliably estimate regional values of $\mathrm{L}-\mathrm{Cv}$ and $\mathrm{L}-$ 408 skewness.

409 Using this criteria, and considering that for a homogeneous sub-region there is little 410 advantage in having more than 20 stations (Hosking and Wallis, 1997), eight homogeneous 411 sub-regions were defined. This number of subregions allows for a sufficient optimization of 412 Eq. 3 using the least square difference technique. Within the eight sub-regions, the stations 413 were assigned according to the magnitude of MAP arranged in ascending order. Each sub414 region had an average of 21 stations and 638 station-years of record.

415 As suggested by Schaefer et al. (2008) and Wallis et al. (2007), forming homogeneous 416 regions is an iterative process. Table 2 presents the eight homogeneous sub-regions, 417 obtained after three iterations. These iterations resulted in the elimination of four stations 418 that were discordant and moving three stations from one sub-region to another due to high 419 discordancy. Table 2 also lists sub-regions 9 and 10 that were formed at the extreme ends 420 of the range of MAP to assist in describing the predictor equation for L-Cv and L-skewness 421 (Eq. 3).

422 Computation of the heterogeneity measure H1 showed the final eight sub-regions to be 423 acceptably homogeneous. Of the 168 stations included in the eight homogeneous sub424 regions, only three stations (each in different sub-regions) had a discordancy value above 425 the Di critical value of 3 (Station Alicahue: $\mathrm{Di}=3.9$, Station Ramadilla: $\mathrm{Di}=3.7$ and 426 Station San Antonio: Di = 3.4). All stations are mildly discordant and it was decided to 427 keep them as part of the collection of stations for the sub-regions.

\subsection{Stage 3: Selection of regional probability distribution}

430 As a first step in selecting the best-fit regional probability distribution by using graphical 431 methods, including the L-moment ratio diagram (Peel et al., 2001; Vogel and Fennessey, 
432 1993), Fig. 3 shows the L-Skewness vs L-Kurtosis ratio diagrams generated by L-RAP for 433 the eight homogeneous sub-regions. It is seen that the center of the cloud of L-skewness 434 and L-kurtosis pairs for all sub-regions, is located near the Gaucho distribution curve. 435 However, a given sub-region may also plot close to the GEV distribution or Pearson Type 436 III. Less proximity was found to the Generalized Pareto distribution and even less to the 437 Generalized Logistic. This suggests that the Gaucho distribution is a good fit to the 438 observed data for the collection of sub-regions.

439 However, as Hosking and Wallis (1997) and Peel et al. (2001) suggest, visual examination 440 of the L-moment ratio diagram should not be the sole criterion when choosing the best-fit 441 distribution, but should include a goodness-of-fit measure for identification of acceptable 442 distributions. Accordingly, Table 2 presents the best-fit distributions for the eight proposed

443 homogeneous sub-regions based on the $\mathrm{Z}^{|\mathrm{DIST}|}<1.64$ goodness-of-fit test. The distributions, 444 in order of highest to lowest goodness-of-fit were Gaucho, Pearson Type III, Generalized 445 Normal, Generalized Extreme Value and Generalized Pareto. The only common 446 distribution to the eight homogeneous sub-regions was the Gaucho distribution. This 447 confirms the point made by Hosking and Wallis (1997) that the 4-p-Kappa distribution, 448 source of the Gaucho distribution, has a high degree of flexibility to adapt to a variety of 449 distribution models. The 4-p-Kappa distribution is a generalization of a number of other 450 commonly used distributions in hydrology, like the generalized logistic, the generalized 451 extreme-value or the generalized Pareto (Finney, 2004; Hosking, 1994).

453 3.2.4. Stage 4: Parameter and quantiles estimation

454 Table 3 presents the values of the parameters of location $\xi$, scale $\alpha$, and the shapes $\kappa$ and $455 h$ (set to 0.50 ), of the Gaucho distribution. It also includes the values of the same four 456 parameters obtained by fitting the 4-p-Kappa distribution. Between the northern arid 457 boundary and the southern subhumid boundary of the study area, the location parameter $\xi$ 458 increased from 0.43 to $0.67, \alpha$ decreased from 0.69 to 0.59 and $\kappa$ increased from -0.03 to 459 0.36. Thus, the Gaucho distribution has enough flexibility to adapt to the behavior of the 460 annual precipitation data across the study area. For the 4-p-Kappa distribution, $\xi$ increased 
461 from 0.25 to $0.75, \alpha$ decreased from 0.87 to $0.47, \kappa$ increased from 0.07 to 0.25 and $h$ 462 decreased from 0.82 to 0.28 .

463 The results in Table 3 indicate a minor change in the shape of the regional probability 464 distribution, closer to the Generalized Pareto on the northern boundary to a GEV or 465 Generalized Normal near the southern boundary. The average 4-p-Kappa $h$ value for the 466 eight homogeneous sub-regions was 0.45 , which is very close to the value $h=0.50$ set for 467 the Gaucho distribution.

468 In addition, the $\kappa$ parameter values of the eight sub-regions, the value $h=0.50$ in the case 469 of the Gaucho distribution, and the $h$ parameter values of the eight sub-regions in the case 470 of the 4-p-Kappa distribution fit, are all located near the center of the parameter space that 471 ensures the existence of the L-moments (Hosking, 1994; Winchester, 2000). They are also 472 located in a region of the parameter space in which the bias and RMSE in quantile 473 estimation using L-moments is significantly less than that obtained with the maximum 474 likelihood estimation method (Dupuis and Winchester, 2001). This suggests that the RFA475 LM produces more robust estimates in the study area than those obtained by conventional 476 methods based on at-site and/or using maximum likelihood or product-moment estimation 477 methods.

478 Table 4 lists the regional quantiles for each of the eight homogeneous sub-regions, obtained 479 from the Gaucho distribution. It can be seen that from sub-region 1 to sub-region 8, there is 480 a reduction in the variability in quantile estimates. This is related to the reduction of the 481 Gaucho distribution scale parameter $\alpha$ from 0.69 to 0.59 in the North-South direction, and 482 is associated with a decreasing trend from North to South of L-Cv, L-kurtosis and L483 skewness, as shown in Table 2. In this way, more frequent extremes can be expected in the 484 drier areas than in the wetter climates of the study area. This behavior is similar to that 485 described by Schaefer et al. (2008) and Wallis et al. (2007). It also coincides with the fact 486 that there is a high interannual rainfall variability within arid and semiarid regions (Kalma 487 and Franks, 2003) and is fully consistent with the analysis of dry year frequency for the 488 Chilean territory made by Gastó (1966). The latter, categorizing the years from very dry to 489 very wet, found a higher frequency of dry or very dry years (42\% of all years) in the 490 northern arid zone near the study area and a lower frequency (27\%) in the southern, 
491 subhumid regions. These results indicate the importance of selecting the appropriate

492 probability distribution in the analysis of annual meteorological drought, at least in semi-

493 arid regions with high gradients of interannual variability from dry to more humid zones.

494 Some authors, although implementing the RFA-LM for distribution fitting of annual

495 precipitation in their study areas with similar or higher precipitation gradients than this

496 study (Yue and Hashin, 2010), or placed in other semiarid regions (Vicente-Serrano, 2006),

497 did not confirm the homogeneity assumption in their analysis. This can result in a mis-

498 specification of the regional distribution as well as an increase in the bias of the estimates

499 solely due to using a heterogeneous region, which is inconsistent with the basic assumption

500 of the index flood regional frequency analysis (Stedinger et al., 1993; Reed et al., 1999).

502 3.2.5. Stage 5: Drought return period mapping

503 3.2.5.1. Predictor equations for spatial mapping of L-Cv and L-skewness

504 Plots of the predictor equations for L-moment ratios as a function of MAP, together with

505 the parameters and goodness-of-fit measures are shown in Fig. 4. The general goodness-of-

506 fit for L-Cv and L-skewness is visually evident. Greater variability is seen for the regional

507 L-kurtosis values, which is a characteristic inherent to the higher moments. The solutions

508 for $\mathrm{L}-\mathrm{Cv}$ and L-skewness are particularly important because the quality of those 509 relationships largely determines the reliability of quantile estimates for 3-parameter 510 probability distributions such as the Gaucho distribution.

$512 \quad 3.2 .5 .2$. Annual meteorological drought return period map

513 The L-Cv and L-skewness maps of the study area are shown in Fig. 5. The L-kurtosis map 514 is not included, because the Gaucho distribution has only three parameters and can be 515 calculated only from L-moment 1 (MAP), L-Cv and L-skewness. There is a decreasing 516 trend of L-Cv and L-skewness (derived from the best-fit curves previously obtained in Fig.

517 4) from the northern edge to the southern edge of the study area. The decrease in L-Cv and 518 L-skewness along the North-South axis is also associated with a decrease, in the same 519 direction, of the variability in the regional growth curve in the left tail and especially the 
right tail as was seen in Table 2. Therefore, if the comparison is made with respect to the

521 average value of precipitation, as the Index Flood scaling factor, the probability of very dry

522 or wet years is greater at the northern edge and is lower on the southern edge of the study

523 area. For example, a 0.4 quantile of the regional growth curve (equivalent to $40 \%$ of

524 normal) had a probability of exceedance of 0.23 in sub-region 1, equivalent to a return

525 period of approximately four years. In contrast, the same quantile in sub-region 8 , had a

526 probability of exceedance of 0.05 , equivalent to a return period of about 18 years. In the

527 upper tail of the regional growth curve the difference is even larger: a quantile of 2 ,

528 equivalent to twice the MAP, in sub-region 8 is seen on average once every 100 years,

529 whereas in sub-region 1, it happens on average once every 10 years.

530 Drought return period maps for $80 \%$ and $40 \%$ of the normal are presented in Figs. $6 a$ and

$5316 \mathrm{~b}$ respectively. The results indicate that, on average, the $80 \%$-of-the-normal drought has

532 similar return periods along the study area, with a minimum of two years around the

533 northern edge and about three years at the southern edge. These similarities are due to the

534 small differences between the quantiles of the regional growth curves around the central

535 values of the distribution.

536 In contrast, a 40\%-of the-normal drought occurs between three and four years on average 537 at the northern edge and every 22 years at the southern one. That is, higher aridity implies 538 more recurrence of extreme annual drought events. The spatial distribution of drought 539 frequency agrees with previous studies that analyzed the frequency of dry years in Chile 540 (Gastó, 1966).

541 The map also allows us to appreciate a decreasing frequency component from coast to 542 mountains, associated with increased precipitation in that direction. This means that coastal 543 drylands have a greater frequency of droughts than foothill drylands. Between parallels $33^{\circ}$ 544 and $35^{\circ} \mathrm{S}$ a distinct pattern in the frequency can also be seen, compared with the area north 545 of latitude $33^{\circ} \mathrm{S}$. This is because the terrain topography changes from the type known as 546 transverse valleys, between parallels $29^{\circ}$ and $33^{\circ} \mathrm{S}$, to the type referred to as longitudinal 547 valleys, southwards of $33^{\circ} \mathrm{S}$. The orographic effect that influences the distribution of 548 annual precipitation in that location, which increases to the West in the coastal mountain 549 range, is reduced again in the longitudinal valleys, and increases again towards the East, 
towards the mountains of the Andes (Falvey and Garreaud, 2007). This pattern is reflected

551 in the spatial distribution of the drought return period, where higher frequencies enter into 552 the center of the valley around the parallel $33.4^{\circ} \mathrm{S}$. The map also allows us to determine 553 locations with greater frequency of droughts, which can be used in the preparation of 554 drought vulnerability maps (Luers, 2005) or risk maps (Wilhite and Buchanan-Smith, 555 2005), useful for decision making support and climate risk management. For example, 556 while the years with annual precipitation deficits are more common toward the north, 557 economically important rain-fed farming presents a diametrically opposite distribution. The 558 North is predominantly associated with livestock raising goats on farmers communal land 559 (MINAGRI-INDAP-PRODECOP, 2001), while rainfed agriculture is much more 560 developed towards the southern boundary. There are more options for cropping, and greater 561 land area is used for agricultural crops, including wheat, and for improved natural 562 grasslands and sown pastures for raising sheep and cattle. Under these conditions, a drought 563 of $40 \%$--of-the-normal does not cause the same impact as in the North. Therefore, it is 564 important to define different drought thresholds throughout the study area. This contrasts 565 with the drought definition established nowadays by Chilean legislation, which uses for a 566 significant proportion of the study area a single Percent to Normal and a single accumulated 567 precipitation return period value to define extreme water scarcity events (DGA, 1984). In 568 this regard, as indicated by Steineman et al. (2005), the drought definition used in this study 569 does not consider the different impact that the same precipitation deficit level has in 570 different regions, but it has the advantage of obtaining return periods for a given quantile, 571 and it is the end user who can turn that quantile to the drought indicator of choice. In 572 addition, the percentage with respect to the normal is a widely adopted drought indicator 573 that can be related to quantiles and percentiles, and is considered one of the best available 574 drought indicators, as a complement to the commonly used Standardized Precipitation 575 Index (Keyantash and Dracup, 2002; Quiring, 2009a,b).

576 The results of this study also enable us to determining the frequency of the most important 577 droughts, i.e. those reported to have had the greatest economic impacts in north-central 578 Chile, such as e.g., the 1968 and 1997 droughts (Espinoza and Hajeck, 1988; Fernández et 579 al., 1997). In those years, annual precipitation in north-central Chile was between 20-30\% 580 of a normal year. Based on the regional growth curves presented in Table 4, a quantile of 
5810.3 is equivalent to a $30 \%$ drought, and has a return period of approximately six years at the 582 northern edge, 24 years in the central study area and 68 years in the far South. Therefore, it 583 is important that legislation considers the enormous variability in the definition of drought 584 being used throughout this study area.

585 Finally, if one includes also the concept of sensitivity, adaptive capacity and vulnerability 586 (Luers et al., 2003), along with the frequency of occurrence of drought as a stressful event, 587 then the risk or vulnerability of the area should have a high spatial variability along the 588 gradient of mean annual rainfall.

\section{Conclusions}

591 In this study, a methodology was developed to use a RFA-LM procedure for estimating the 592 spatial distribution of drought frequency in northern-central Chile, in a transition between 593 arid and sub-humid areas of the country. Based solely on the use of monthly precipitation 594 records, it was possible to identify homogeneous sub-regions along the study area, which 595 were fitted by different probability distribution models. The model that best fit the entire 596 area was the Gaucho distribution, which was defined in this study as a special case of the 4597 p-Kappa distribution. The use of this model allows identifying a gradient of drought 598 frequency along the study area which depends on the considered drought level. Thus, while 599 the frequencies of $80 \%$-of-the-normal droughts are relatively similar throughout the area, 600 those of $40 \%$-of-the-normal result in differences in about four orders of magnitude. A 601 drought defined as 30\%-of-the-normal can have differences of up to 10 orders of magnitude 602 between the northern arid region and the southern subhumid area. Given the high frequency 603 of these extreme droughts at the northern edge of the study area, which is nearly six years, 604 they might better be considered as a structural condition of the region rather than extreme 605 events. As such, it requires a change of management strategy to deal with low precipitation events in this area on a permanent basis.

607 The results also indicate the importance of a homogeneity check, for proper probability 608 distribution selection, especially in drylands along annual precipitation gradients. For 609 example, a proper selection of the distribution model used in drought indices based on 610 frequency analysis, such as the widely used Standardized Precipitation Index, could be 
611 critical for extreme drought events detection, especially for annual values in arid zones

612 based on this drought index. The proposed methodology allows more robust estimation of

613 quantiles compared with conventional methods. Its representation in terms of practical

614 drought frequency maps can be used by water resource managers for decision making. The

615 maps obtained indicate the need to consider the use of different thresholds of drought

616 throughout the study area, which, together with drought vulnerability maps, could generate

617 drought risk maps to guide differentiated strategies in drought management along the

618 North-South axis of central Chile.

619 On the other hand, when drought frequency has to be determined for some specific drought 620 events in ungauged sites, the procedure presented in this study will yield better estimates 621 than any other available method. With this procedure, there is no need to have long time 622 series of station data to develop a drought monitoring network, as in an at-site approach, 623 because the RFA-LM analysis allows pooling stations to construct a stronger basis for 624 selecting correct distributions and their quantiles. Therefore, this methodology should be of 625 practical value for these regions that lack abundant climate data sets, but suffer from high 626 drought frequency, as is common in arid and semi-arid regions throughout the world.

\section{Acknowledgements}

629 The authors wish to express their appreciation to the Government of Flanders, the 630 UNESCO International Hydrological Programme, the IWR of the U.S. Army Corps of 631 Engineers, and the Water Center for Arid and Semiarid Zones of Latin America and the 632 Caribbean (CAZALAC). Also, and especially, we are grateful to the General Water

633 Directorate of Chile and the Chilean Meteorological Office, who provided all necessary 634 climate information for this analysis.

\section{Appendix - Brief overview of the RFA-LM methodology development}

637 Many practical problems require the fitting of a probability distribution to a data sample. In 638 many fields of application the available data do not consist of a single sample, but a set of 639 samples drawn from similar sites that can be expected to have similar probability distributions. The distribution for one sample can be more accurately estimated by using 
641 information, not only from that sample, but also from the other related samples. In

642 environmental sciences, data samples are typically measurements of the same kind of data

643 made at different sites, and the process of using data from several sites to estimate the

644 frequency distribution is known as regional frequency analysis.

645

646 In the early 1970s, there was a growing awareness among hydrologists that annual

647 maximum stream flow data, although commonly modeled by the Gumbel distribution, often

648 had higher skewness than was consistent with that distribution. Moment statistics were

649 widely used as the basis for identifying and fitting frequency distributions, but to use them

650 effectively required knowledge of their sampling properties in small samples. A massive

651 (for the time) computational effort using simulated data was performed by Wallis et al.

652 (1974). It revealed some unpleasant properties of moment statistics: high bias and algebraic

653 boundedness.

654

655 In hydrology and meteorology, having a sequence of values observed at a site that is 656 normally distributed is rare, while skewed distributions are quite commonly observed. 657 Unfortunately the estimate of the skew coefficient, G, is mathematically constrained, a fact 658 which has been known since 1944, but frequently forgotten or ignored by practitioners. For 659 instance, consider samples of length 30 taken from a Type I Extreme Value Distribution 660 with mean 2600, standard deviation 800 and skewness 10; the constraint on the estimate of 661 the skew coefficient is solely a function of the sample size, $\mathrm{n}$ :

$$
G=\frac{n-2}{\sqrt{n-1}}
$$

663 The maximum value $\mathrm{G}$ is therefore 5.2 for a sample of 30 when the true skewness 664 coefficient was 10.

665

666 Attempting to try and select the true parent distribution from single samples by using a 667 conventional goodness-of-fit measure can be perilous to say the least. In Table 5 the results 668 are given of an experiment where samples from an Extreme Value type I (EV I) distribution 669 were generated and with the best fit being chosen based upon minimum mean squared 
670 deviation for three distribution: EV I, Log Normal, and the Normal distribution. Note that

671 even with a sample size of 90 the correct distribution was chosen only $40 \%$ of the time.

673 In contrast, the higher L--moments are not constrained by sample size and their estimates 674 have small bias and small range of -1 to +1 . This is a strong argument for regionalization, 675 and if the region is homogeneous we can expect that the extreme quantile estimates 676 obtained will be better than those made with any at-site estimator. Matalas et al. (1975) 677 went on to establish the phenomenon of 'separation of skewness', which is that for annual 678 maximum stream flow data the relationship between the mean and the standard deviation of regional estimates of skewness for historical flood sequences is not compatible with the

680 relations derived from several well known distributions. Separation can be explained by 681 'mixed distributions' (Wallis et al., 1977) - regional heterogeneity in our present 682 terminology - or if the frequency distribution of stream flow has a longer tail than those of 683 the distributions commonly used in the 1970s. In particular, the Wakeby distribution, which 684 was devised by H.A. Thomas Jr. (personal communication to J.R. Wallis, 1976), does not 685 exhibit the phenomenon of separation (Landwehr et al., 1978). It is hard to estimate by 686 conventional methods such as maximum likelihood or the method of moments, and the 687 desirability of obtaining closed-form estimates of Wakeby parameters led Greenwood et al., 688 (1979) to devise Probability Weighted Moments, PWMs. They were found to perform well 689 for other distributions (Landwehr et al., 1979; Hosking et al., 1985b; Hosking and Wallis, 690 1987), but were hard to interpret. Later, Hosking (1990) found that certain linear 691 combinations of PWMs, which he called 'L-moments', could be interpreted as measures of 692 the location, scale, and shape of probability distributions and formed the basis for a 693 comprehensive theory of the description, identification, and estimation of distributions.

695 The modern use of the index-flood procedure stems from Wallis (1981, 1982), who used it 696 in conjunction with PWMs and the Wakeby distribution as a method of estimating quantiles 697 in the extreme upper tail of the frequency distribution. Comparative studies showed that 698 this 'WAK/PWM' algorithm and analogs in which other distributions were fitted, 699 outperformed the quantile estimation procedures recommended in the U.K. Flood Studies 700 Report (Hosking et al., 1985a) and the U.S. 'Bulletin 17' (Wallis and Wood, 1985). Later 
701 work investigated the performance of this index flood procedure in the presence of 702 archeological and historical data (Hosking and Wallis, 1986a,b), regional heterogeneity 703 (Lettenmaier et al., 1987), and intersite dependence (Hosking and Wallis, 1988). The 704 practical utility of regional frequency analysis using this index-flood procedure, however, 705 still required subjective judgment at the stages of formation of the regions and choice of an 706 appropriate frequency distribution for each region; statistics to assist with these judgments 707 were developed by Hosking and Wallis (1993).

708 The first of these statistics, called $\mathrm{D}_{\mathrm{i}}$ for Discordancy, measured the dispersion of the 709 sample 1-moment ratios (L-Cv, L-Skewness, and L-Kurtosis) of a site in three-dimensional 710 space. A group of sites will yield a cloud of such points and any point that is far from the 711 center of the cloud will be flagged as discordant. The formal definition can be found on 712 page 46 of Hosking and Wallis (1997).

713

714 The second statistic, H1, estimates the degree of heterogeneity in a group of sites to assess 715 whether the sites might reasonably be treated as a homogeneous region. Specifically, the 716 heterogeneity measure compares the between-site variations in sample L-moments for the 717 group of sites with what would be expected for a homogeneous region. The formal 718 definition can be found on page 63 of Hosking and Wallis (1997). Once a homogeneous 719 region has been verified one can proceed to the next step, identifying the most likely 720 regional distribution.

722 The third statistic, $Z^{|\mathrm{DIST}|}$, is used to test whether any given distribution fits the regional data 723 acceptably closely. The formal definition can be found on page 81 of Hosking and Wallis 724 (1997). Several distributions may fit the regional data quite adequately. Luckily, when this 725 has been observed, the distributions chosen have great similarity in their CDF's and 726 departure is often only of importance at very extreme quantiles. 
730 Abdul-Moniem, I., Selim, Y., 2009. TL-Moments and L-Moments Estimation for the

731 Generalized Pareto Distribution. Appl. Math. Sciences. 3(1), 1943-1952.

732 Aceituno, P., 1992. Anomalías de la precipitación en Chile central relacionadas con la

733 Oscilación del Sur: Mecanismos asociados, in: Ortielb, L., Machares, J. (Eds.), Paleo

734 ENSO records. International Symposium. Lima. Extended Abtstracts, pp. 1-5.

735 Asquith, W., 2009. Package 'Imomco'. L-moments, Trimmed L-moments, L-comoments,

736 and Many Distributions. R CRAN,

737 <http://cran.r-project.org/web/packages/lmomco/index.html > (accessed 18.11.09).

738 Baldassarre, G., Castellarin, A., Brath, A., 2006. Relationships between statistics of rainfall 739 extremes and mean annual precipitation: an application for design-storm estimation in 740 northern central Italy. Hydrol. Earth Syst. Sci, 10, 589-601.

741 Below, R., Grover-Kopec, E., Dilley, M., 2007. Documenting Drought-Related Disasters.

742 A Global Reassessment. J. Environ. Development. 16 (3), 328-344

743 Bonnin, G.M., Martin, D., Lin, B., Parzybok, T., Yekta, M., Riley, D., 2006. Precipitation 744 Frequency Atlas of the United States. NOAA Atlas 14. Volume 3 version 4.0: Puerto Rico 745 and the U.S. Virgin Islands.

746 Brath, A., Castellarin, A., Franchini, F., Galeati, G., 2001. Estimating the index flood using 747 indirect methods. Hydrol. Sci. J. 46 (3), 399-418.

748 Burn, D.H., Goel, N.K., 2000. The formation of groups for regional flood frequency 749 analysis. Hydrol. Sci. J. 45 (1), 97-112.

750 Chavochi, S., Soleiman, W.N.A., 2009. Delineating Pooling Group for Flood Frequency 751 Analysis Using Soft Computing. Eu. J. Sci. Res. 35 (2), 181-187.

752 Chow, V.T., Maidment, D.R., Mays, L.W., 1994. Applied Hydrology. McGraw-Hill, Santa 753 Fé de Bogotá (spanish version).

754 Ciumara, R., 2007. L-moments for evaluation in distributed identically and nonidentically 755 weibull random variables. Proceedings of the Romanian Academy, Series A. 8 (3), 1-6. 
756 Clarke, R., 2010. On the (mis)use of statistical methods in hydro-climatological research.

757 Hydrol. Sci. J. 55 (2), 139-144.

758 Delicado, P., Goria, M.N., 2007. A small sample comparison of maximum likelihood,

759 moments and L-moments methods for the asymmetric exponential power distribution.

760 Comput. Stat. Data Anal.. 52,1661 - 1673.

761 Demuth, S., Külls, C., 1997. Probability Aspects of analysis and regional droughts in

762 southern Germany. Resources under Increasing Sustainability of Water Uncertainly

763 (Proceedings of Rabat Symposium SI, April 1997). IAHS Publ. 240, 97-104.

764 DGA., 1984. Established criteria for qualifying times of extraordinary drought (in Spanish).

765 Water Directorate, Ministry of Public Works, Republic of Chile.

766 Di Castri, F., Hajek, E., 1976. Bioclimatología de Chile. Vicerrectoría Académica 767 Universidad Católica de Chile, Santiago.

768 Dingman, L.S., 2001. Physical Hydrology, Prentice Hall Inc, New Jersey.

769 Dupuis, D.J., Winchester, C., 2001. More on the four-parameter kappa distribution. J. Stat. 770 Comp. Sim. 71(2), 99-113.

771 Escobar, F., Aceituno, P., 1998. Influencia del fenómeno ENSO sobre la precipitación 772 nival en el sector andino del Chile central durante el invierno. Bull. Inst. fr. Études andines. $77327(3), 753-759$.

774 Espinosa, G., Hajek, E., 1988. Climate Risk: Evidence in central Chile, in: Fuentes, E., 775 Peñafrena, S., (Eds.) Landscape ecology in Central Chile: Studies on its mountain areas (in 776 Spanish). Universidad Católica de Chile, Santiago.

777 Falvey, M., Garreaud, R., 2007. Wintertime Precipitation Episodes in Central Chile: 778 Associated Meteorological Conditions and Orographic Influences. J. Hydrometeorol. 8, 779 171-193.

780 Fernández, B., Donoso, G., Luraschi, M., Orphanopolous, D., Salazar, C., 1997. 781 Estimating the economic impact associated with hydrological droughts (in spanish). VI 782 Jornadas CONAPHI, Chile, Santiago. 
783 Fernández, B., Vergara, A., 1998. Risk of scarcity of monthly precipitation and 784 streamflows in semiarid regions. Hydrol. Sci. J. 43 (5), 759-773.

785 Finney, J., 2004. Optimization of a Skewed Logistic Distribution with Respect to the 786 Kolmogorov-Smirnov test. PhD, Agricultural and Mechanical College, Louisiana State.

787 Fuentes, E., Evans, G., Hajeck, E., 1988. Some consequences of rainfall variability for 788 Mediterranean-type Ecosystems in Chile., in: di Castri, F., Floret, Ch., Rambal, S. and Roy, 789 J., Time Scale and Water Stress. Proceedings of the $5^{\text {th }}$ International Conference on 790 Meditarranean Ecosystems. The International Union of Biological Sciences, Paris, pp. 347791360.

792 Gaál, L., Kyselý, J., 2009. Regional frequency analysis of heavy precipitation in the Czech 793 Republic by improved region-of-influence method. Hydrol. Earth Syst. Sci., 6, 273-317.

794 Gaál, L., Kyselý, J., Szolgay, J., 2008. Region-of-influence approach to a frequency 795 analysis of heavy precipitation in Slovakia. Hydrol. Earth Syst. Sci., 12, 825-839.

796 Garreaud, R., Rutllant, J., 1997. Summer rainfall in the Andes of central Chile: 797 climatological aspects. Atmosphere, 10, 191-211.

798 Gastó, J.M. 1966. Variaciones de las precipitaciones anuales en Chile. Bol. Téc. Fac. 799 Agron. Univ. Chile 24, 4-20.

800 Greenwood, J.A., Landwehr, J.M., Matalas, N.C., Wallis, J.R., 1979. Probability weighted 801 moments: Definition and relation to parameters of several distributions expressable in 802 inverse form. Water Resour. Res. 15, 1049-1054.

803 Hallack-Alegria, M., Watkins, D.W., 2007. Annual and Warm Season Drought Intensity804 Duration-Frequency Analysis for Sonora, Mexico. J. Climate, 20 (9), 1897-1909.

805 Hisdal, H., Tallaksen, L., 2003. Estimation of regional meteorological and hydrological 806 drought characteristics: a case study for Denmark. J. Hydrol. 281, 230-247.

807 Hosking, J.R.M., 1990. L-moments: Analysis and estimation of distributions using linear 808 combinations of order statistics. J. Roy. Statistical Society, Series B, 52, 105-124.

809 Hosking, J.R.M., 1994. The four-parameter Kappa distribution. IBM. J. Research 810 Development. 38 (3), 251-258. 
811 Hosking, J.R.M., 2005. FORTRAN routines for use with the method of L-moments,

812 Version 3.04. IBM Research Report RC12822, IBM Research Division, Yorktown Heights,

813 New York.

814 Hosking, J.R.M., 2009a. Package L-moments. CRAN Repository.

815 <http://cran.r-project.org/web/packages/lmom/index.html> (accessed 18.11.09).

816 Hosking, J.R.M., 2009b. Package 'ImomRFA'. Regional Frequency Analysis using L-

817 moments. CRAN Repository.

818 <http://cran.r-project.org/web/packages/lmomRFA/lmomRFA.pdf > (accessed 18.11.09).

819 Hosking, J.R.M., Wallis, J.R., 1986a. Paleoflood hydrology and flood frequency analysis.

820 Water Resour. Res. 22, 543-550.

821 Hosking, J.R.M., Wallis, J.R., 1986b. The value of historical data in flood frequency 822 analysis. Water Resour. Res. 22, 1606-1612.

823 Hosking, J.R.M., Wallis, J.R., 1987. Parameter and quantile estimation for the generalized 824 Pareto distribution. Technometrics 29, 339-349.

825 Hosking, J.R.M., Wallis, J.R., 1988. The effect of intersite dependence on regional flood 826 frequency analysis. Water Resour. Res. 24, 588-600.

827 Hosking, J.R.M., Wallis, J.R., 1993. Soe statistics useful in regional frequency analysis. 828 Water Resour. Res. 29, 271-281.

829 Hosking, J.R.M., Wallis, J.R., 1997. Regional frequency analysis: an approach based on 830 Lmoments. Cambridge University Press, Cambridge, UK, pp 224.

831 Hosking, J.R.M., Wallis, J.R., Wood, E.F., 1985a. An appraisal of the regional flood 832 frequency procedure in the UK Flood Studies Report. Hydrol. Sci. J. 30, 85-109.

833 Hosking, J.R.M., Wallis, J.R., Wood, E.F., 1985b. Estimation of the generalized extreme834 value distribution by the method of probability-weighted moments. Technometrics 27, 251835261.

836 Kalma, J. D., Franks, S.W., 2003. Rainfall in arid and semiarid regions. Chapter 2. In: 837 Simmers, I (Ed). Understanding water in a Dry Environment. Hydrological Processes in 
838 arid and semiarid zones. International Association of Hydrogeologists. Balkema. Lissie. 1583963.

840 Karvanen, J., 2009. Package 'Lmoments'. CRAN Repository, 841 <http://cran.r-project.org/web/packages/Lmoments/index.html> (accessed 18.11.09).

842 Keyantash, J., Dracup, J.A., 2002. The Quantification of Drought: An Analysis of Drought 843 Indices. Bull.Amer. Meteorol. Soc. 83 (8), 1167-1180.

844 Kohnová, S., Hlavčová, K., Szolgay, J., Števková, A., 2009. Seasonality Analysis of the 845 Occurrence of Low Flows in Slovakia. International Symposium on Water Management 846 and Hydraulic Engineering, Ohrid, Macedonia, 1-5 September 2009.

847 Kundu, D., 2001. Generalized exponential distribution: different method of estimations. J. 848 Stat. Comp. Sim., 69 (4), 315-337.

849 Kyselý, J., Gaál, L., Picek, J., 2010. Comparison of regional and at-site approaches to 850 modelling probabilities of heavy precipitation. Int. J. Climatol., doi 10.1002/joc.2182

851 Lana, X., Martinez, M., Burgueño, A., Serra, C., 2008. Return Period maps of dry spells 852 for Catalonia (northeastern Spain) based on the Weibull distribution. Hydrol. Sci. J. 53 (1), $853 \quad 48-64$.

854 Landwehr, J.M., Matalas, N.C., Wallis, J.R., 1978. Some comparisons of flood statistics 855 with some traditional techniques in estimating Gumbel parameters and quantiles. Water 856 Resour. Res. 15, 1361-1379.

857 Landwehr, J.M., Matalas, N.C., Wallis, J.R., 1979. Probability weighted moments 858 compared with some traditional techniques in estimating Gumbel parameters and quantiles. 859 Water Resour. Res. 15, 1055-1064.

860 Le Houérou, H., 1988. Interannual variability of rainfall and its consequences on 861 ecological and managerial natural vegetation, crops and livestok, in: di Castri, F., Floret, 862 Ch., Rambal, S. and Roy, J., Time Scale and Water Stress., Proceedings of the $5^{\text {th }}$ 863 International Conference on Meditarranean Ecosystems. The International Union of 864 Biological Sciences, Paris, pp. 323-346.

865 Lettenmaier, D.P., Wallis, J.R., Wood, E.F., 1987. Effect of regional heterogeneity on flood 866 frequency estimation. Water Resour. Res. 23, 313-323. 
867 Lin, G., Chen, L., 2006. Identification of homogeneous regions for regional frequecy 868 analysis using the self-organizing map. J. Hydrol. 324 (1-4), 1-9.

869 Liou, J.J., Wu, Y.C., Cheng, K.S., 2008. Establishing acceptance regions for L-moments 870 based goodness-of-fit tests by stochastic simulation. J. Hydrol. 355, 49-62.

871 Loucks, D.P., van Beek, E., 2005. Water Resources Planning and Management Systems: 872 An Introduction to Methods, Models, and Applications. UNESCO Press, Paris

873 Loukas, A., Vasiliades, L., 2004. Probabilistic analysis of spatiotemporal drought 874 characteristics in Thessaly region, Greece. Nat. Hazards Earth Syst. Sci., 4, 719-731.

875 Luers, A., Lobell, D., L. Sklar, Addams, C., Matson, P., 2003. A method for quantifying 876 vulnerability, applied to the agricultural system of the Yaqui Valley, Mexico. Global 877 Environ. Change 13, 255-267.

878 Luers, A.L., 2005. The surface of vulnerability: An analytical framework for examining 879 Environmental Change. Global Environmental Change 15, 214-223.

880 Matalas, N.C., Slack, J.R., Wallis, J.R., 1975. Regional skew in search for a parent. Water 881 Resour. Res. 11, 815-26.

882 MINAGRI-AGRIMED-PRODECOP., 2001. Compendium of environmental, socio883 economic and forest or agriculture from the IV Region of Coquimbo (in Spanish). Ministry 884 of Agriculture, Chile, Santiago.

885 Mishra, B.K., Tachikawa, Y., Takara. K., 2007. Suitability of sample size for identifying 886 distribution function in regional frequency analysis. Annuals of disas. Prev. Res. Inst Kyoto 887 Univ. 50(B), 69-74.

888 Modarres, R., 2009. Regional frequency dry spells by L-Moment analysis and multivariate 889 analysis. Water Resour. Manage., DOI 10.1007/s11269-009-9556-5.

890 Morales, L., Canesa, F., Mattar, C., Orrego, R., Matus, F., 2006. Caracterización y 891 zonificación edáfica y climática de la Región de Coquimbo, Chile. J Soil. Sci. Plant. Nutr. $8926(3), 52-74$. 
893 Norbiato, D., Borga, M., Sangati, M., Zanon, F., 2007. Regional frequency analysis of 894 extreme precipitation in the eastern Italian Alps and the August 29, 2003 flash flood. J. 895 Hydrol 345, 149-166.

896 Pearson, C., 1995. Regional frequency analysis of low flows in New Zealand rivers. J. 897 Hydrol (NZ), 33 (2), 94-122.

898 Peel, M.C., Wang, Q., Vogel, R.M., and McMahon, T.A., 2001. The utility of L-moment 899 ratio diagrams for regional selecting a probability distribution. Hydrol Sci. J., 46(1), 147900155.

901 Ponvert-Delisle, D.R., Lau, A., Balamaseda, C., 2007. La vulnerabilidad del sector agrícola 902 frente a los desastres. Reflexiones generales. Zonas Aridas 11(1), 174-194.

903 Quintana, J., 2000. The Drought in Chile and La Niña. Drought Network News, A 904 Newsletter of the International Drought Information Center and the National Drought 905 Mitigation Center, 12 (2), 3-6.

906 Quiring, S., 2009a. Monitoring Drought: An Evaluation of Meteorological Drought Indices. 907 Geography Compass 3 (1), 64-88.

908 Quiring, S., 2009b. Developing Objective Operational definitions for monitoring drought.

909 J. Appl. Meteo. Clim. 48, 1217-1229.

910 Reed, D.W., Jakob, D., Robson, A.J., Faulkner, D.S., Stewart, E.J., 1999. Regional 911 frequency analysis: a new vocabulary. Hydrological extremes: understanding, predicting, 912 mitigating. IAHS Publ. 255, 237-243.

913 Rutllant, J., 2004. Aspects of large-scale atmospheric circulation associated with ENSO 914 cycle 1997 - 1999 and its consequences for the regime of precipitation in central Chile., in: 915 Avaria, S., Carrasco, J., Rutllant, J., and Yanez, E.. (Eds.), El Niño-La Niña 1997-2000. Its 916 Effects in Chile, Valparaíso,pp. 1961-1976.

917 Sankarasubramanian, A., Srinivasan, K., 1999. Investigation and comparison of sampling 918 properties of L-moments and conventional moments. J. Hydrol. 218, 13-34.

919 Schaefer, M.G., 2008. L-RAP: Linear Regional Analysis od Precipitation Software v.1.0, 920 MGS Software,Olympia, WA. 
921 Schaefer, M.G., Barker, B.L., Taylor,G.H., Wallis.J.R., 2008. Regional precipitation-

922 frequency analysis and spatial mapping of 24-hour precipitation for Oregon. Final Report.

923 SPR656. Prepared for Oregon Department of Transportation, MGS Engineering 924 Consultants, Washington, USA.

925 Serinaldi, F., Bonaccorso, B.A., Cancelliere, A., Grimaldi, S., 2009. Probabilistic 926 characterization of drought properties through copulas, J. Phys. Chem. Earth., 34 (10-12), $927 \quad 596-605$.

928 Seth, S., 2003. Human Impacts and management issues in arid and semi-arid regions. 929 Chapter 8., in: Simmers, I (Ed). Understanding water in a dry environment. Hydrological 930 Processes in arid and semiarid zones. International Association of Hydrogeologists. 931 Balkema. Lissie., pp. 289-341.

932 Shawky, A.I., Abu-Zinadah, H.H., 2009. Exponentiated Pareto Distribution: Different 933 Method of estimations. J. Int Contemp. Math. Sciences, 4 (14), 677-693.

934 Squeo, F.A., Tracol, Y., López, D., Gutierrez, J.R., Cordova, A.M. and Elheringer, J.R., 935 2006. ENSO effects on primary productivity in Southern Atacama Desert. Adv. Geosci., 6, $936 \quad 273-277$.

937 Stedinger, J.R., Vogel, R., Foufoula-Georgiou, E., 1993. Frequency Analysis of Extreme 938 Events, Chapter 18, in: Maidment, D.R. (Ed), Handbook of Hydrology. McGraw-Hill, 939 New York.

940 Steinemann, A., Hayes, M., Cavalcanti, L., 2005. Drought Indicators and Triggers. In:

941 Wilhite, D. (Ed.), Drought and Water Crises Science, Technology, and Management Issues, 942 Taylor and Francis Group, Boca Raton.

943 Tallaksen, L., Hisdal, H., 1999. Classification of methods of regional drought streamflow 944 series: the EOF Method and L-moments. Technica Report No. 2. $945<$ http://www.hydrology.uni-freiburg.de/forsch/aride/navigation/publications/publications.ht $946 \underline{m}>$ (accessed 18.07.09)

947 Tallaksen, L.M., Hisdal, H., 1997. Regional analysis of extreme streamflow drought 948 duration and deficit volume., in: A. Gustard, A.; Blazkova, S.; Brilly, M.; Demuth, S.; 949 Dixon, J.; Van Lanen, H.; Llasat, C.; Mkhandi, S.; and Servat, E. (Eds.) FRIEND'97- 
950 Regional Hydrology: Concepts and Models for Sustainable Water Resource Management, 951 Ed. IAHS Publication 246. pp. 141-150.

952 Türk, M., Tatl, H., 2009. Use of the standardized precipitation index (SPI) and a modified

953 SPI for shaping drought probabilities over Turkey. Int. J. Climatol. 29 (15), 2270-2282.

954 Verbist, K., 2010. Manual for the L-Moments Mapping Software L-MAP, version 1.2.2.

955 UNESCO grant 513R1A2000, CAZALAC, La Serena, Chile.

956 Verbist, K., Robertson, A.W, Cornelis, W.M., Gabriels, D., 2010. Seasonal predictability of

957 daily rainfall characteristics in central-northern Chile for dry-land management. J. Appl.

958 Meteor. Climat., 49(9), 1938-1955.

959 Verbist, K., Santibañez, F., Soto, G., Gabriels, D., 2006. Zonation of Water Regimes in

960 Latin America and the Caribbean from a climatic point of view. Technical documents of 961 the UNESCO IHP-LAC 8, La Serena, Chile.

962 Vicente-Serrano, S.M., 2006. Differences in spatial patterns of drought on different time 963 scales: an analysis of the Iberian peninsula. Water Resour. Manage. 20, 37-60.

964 Viglione A., Laio, F., Claps, P., 2007. A comparison of homogeneity tests for regional 965 frequency analysis. Water Resour. Res. Vol 43, W03428, doi:10.1029/2006WR005095.

966 Viglione, A., 2009. Package 'nsRFA'., Non-supervised Regional Frequency Analysis. 967 CRAN Repository. <http://cran.r-project.org/web/packages/nsRFA/index.html>, (accessed 968 18.11.09).

969 Vogel, R.M., Fennessey, N. M., 1993. L-moments diagrams should replace product 970 moment diagrams. Water Resour. Res. 29 (6), 1745-1752.

971 Wallis, J.R., 1981. Risk and uncertainties in the evaluation of flood events for the design of 972 hydraulic structures., in: Piene e Siccità, Guggino, E.,Rossi, G., Todini, E. (Eds.) 973 Fondazione Politecnica del Mediterraneo, Catania, Italy, pp. 3-36.

974 Wallis, J.R., 1982. Hydrologic problems associated with oilshale development., in: 975 Environmental Systems and Management, Rinaldi, S. , North-Holland, Amsterdam, pp. 85976102. 
977 Wallis, J.R., Matalas, N.C., Slack, J.R., 1974. Just a Moment! Water Resour. Res. 10, 211 978219.

979 Wallis, J.R., Matalas, N.C., Slack, J.R., 1977. Apparent regional skew. Water Resour. Res. 980 13, 159-182.

981 Wallis, J.R., Schaefer, M.G., Barker, B.L., Taylor, G.H., 2007. Regional precipitation982 frequency analysis and spatial mapping for 24-hour and 2-hour durations for Washington 983 State. Hydrol. Earth Syst. Sci, 11 (1), 415-442.

984 Wallis, J.R., Wood, E.F., 1985. Relative accuracy of log Pearson III procedures. J. Hydraul. 985 Eng. 111, 1043-1056.

986 Werick, W.J., 1995. National Study of Water Management During Drought. IWR Report 987 94-NDS-12. Water Resources Center, U.S. Army Corps of Engineers. Fort Belvoir, VA.

988 Wilhite, D., Buchanan-Smith, M., 2005. Drought as hazard: understanding the natural and 989 social context., in: Wilhite, D. (Ed.). Drought and Water Crises: Science, Technology, and 990 Management Issues, Taylor and Francis Group, Boca Raton.

991 Winchester, C., 2000. On the estimation of the four parameter Kappa distribution. MSc. 992 Thesis, Department of Mathematics and Statistics, Dalhousie University. Nova Scotia, 993 Canada.

994 WMO, 1994. Guide to Hydrological Practices. World Meteorological Organization. WMO$995 \quad \mathrm{~N}^{\circ} 168$.

996 Yue, S., Hashim, M., 2010. Probability distribution of annual, seasonal and monthly 997 precipitation in Japan. Hydrol Sci. J. 52 (5), 863-877.

998 Yurekli, K., Anli, A.S., 2008. Analyzing drought based on annual total rainfalls over Tokat 999 province. International Journal of Natural and Engineering Sciences, 2 (2): 21-26. 


\section{Figure Captions}

1002 Figure 1 Map of the study area (north-central Chile) indicating mean annual precipitation 1003 and the spatial distribution of the 180 raingauge stations.

1004 Figure 2 Histogram and descriptive statistics of (a) Seasonality Index and (c) Julian Mean

1005 Day and scatterplots and linear regression equations between (b) Seasonality Index and 1006 Mean Annual Precipitation and (d) between Julian Mean Day and Mean Annual 1007 Precipitation.

1008 Figure 3 L-moment ratio diagrams for L-skewness vs. L-kurtosis for homogeneous sub1009 regions 1 to 8.

1010 Figure 4 Best fit curves for (a) L-Cv versus Mean Annual Precipitation, (b) L-skewness vs. 1011 Mean Annual Precipitation and (c) L-kurtosis vs. Mean Annual Precipitation.

1012 Figure 5 Map of spatial distribution over the study area (north-central Chile) of (a) L-Cv 1013 and (b) L-skewness..

1014 Figure 6 Map of the drought return period for (a) $80 \%$ of average precipitation and (b) $40 \%$ 1015 of average precipitation. 